\title{
La diplomacia de la reciprocidad: comercio y política entre México y Estados Unidos, 1875-1897*
}

En el último cuarto del siglo XTX el proceso de integración comercial entre México y Estados Unidos planteó la cuestión de adoptar un régimen arancelario especial para el intercambio entre los dos países. El gobierno estadunidense

hizo intentos recurrentes de negociar con el gobierno mexicano un tratado de reciprocidad comercial. Este trabajo analiza las negociaciones bilaterales y las posturas mexicanas, con el propósito de evaluar la capacidad de defender los intereses comerciales en una relación altamente asimétrica.

$\mathbf{U}$ no de los principales rasgos de la relación comercial entre México y Estados Unidos, en perspectiva de largo plazo, ha sido la búsqueda de un régimen arancelario especial que fijara un marco preferencial para la integración comercial entre vecinos. En el siglo XX, ello se concretó en dos grandes ocasiones. La primera fue

*Agradezco las observaciones críticas y sugerencias de Carmen Collado, Alma Parra, Ana Rosa Suárez y Steve Topik. Diana Corzo González me ha auxiliado en la investigación. En este texto, el término "estadunidense" se usa como sinónimo de."norteamericano". el acuerdo de 1942, fraguado durante la segunda guerra mundial bajo los argumentos de una cooperación políticomilitar, y que fue abrogado, sin embargo, una vez terminada la emergencia bélica. La segunda es la del Tratado de Libre Comercio de América del Norte, que en la última década del siglo ha sentado las bases para la integración de un espacio económico continental.

En el siglo XIX, esta búsqueda estuvo pendiente durante la segunda mitad de la centuria y tomó la forma de intentos recurrentes, aunque infructuosos, de instaurar un régimen de reciprocidad: el de un instrumento jurídico que 
eliminaba cuotas arancelarias a favor del otro país por medio de un tratado que concedía admisión libre a ciertos productos. ${ }^{1}$ El significado era la apertura por medio de un pacto político de brechas bilaterales entre dos mercados fuertemente protegidos, pero también contiguos. La historiografia no ha prestado suficiente atención a esta relación entre México y Estados Unidos; como consecuencia, varios aspectos resultan ignorados y otros, como algunas negociaciones, son examinados como hechos extraordinarios que parecen tener escasa relación con el contenido económico bilateral. El cuadro 1 recoge las coyunturas de emergencia de la reciprocidad comercial, el contexto político-económico en que se originaron, el tipo de negociaciones y los resultados a que dieron lugar.

Como se puede ver en el cuadro 1 , el asunto emergió cinco veces en el periodo analizado: con intervalos desiguales pero suficientes para acompañar en cada década las relaciones comerciales entre los dos países, desde la presidencia de Juárez hasta finales del siglo XIX. En términos generales los intentos estadunidenses de arreglos comerciales, no sólo con México, tuvie-

\footnotetext{
${ }^{1}$ El uso del término "reciprocidad" en la segunda mitad del siglo xIx, en la diplomacia comercial de Estados Unidos, se refería a "arreglos dirigidos a aumentar el intercambio de mercancias por medio de reducciones arancelarias mutuas o equivalentes", Moore, Principles, 1918, p. 161. En este texto, cuando se habla de "tratado comercial" se hace referencia a la reciprocidad a través de concesiones arancelarias. Es importante distinguir esto de los tratados de amistad y comercio, que estipulaban la cláusula de la nación más favorecida pero no tenían implicaciones arancelarias.
}

ron una efectividad escasa o nula. Este resultado se atribuye generalmente al carácter partidista de la cuestión en Estados Unidos: la reciprocidad y su contenedor, el arancel, estuvieron sujetos a los vaivenes del ciclo político y de los equilibrios entre demócratas y republicanos en el Congreso. ${ }^{2}$

La propuesta de la reciprocidad fue dirigida al menos dos veces por Estados Unidos a otros estados latinoamericanos, además de México; ${ }^{3}$ pero éste fue el único país que registró una continuidad y una frecuencia del problema en su agenda comercial, probablemente tan elevadas como Canadá. ${ }^{4}$ En vista de las características de duración, recurrencia y diferenciación, analizar las hipótesis de reciprocidad bilateral ofrece la posibilidad de enfocar la política y la estrategia comercial mexicana frente a Estados Unidos. No obstante la escasa efectividad final, las iniciativas de reciprocidad plantearon problemas relevantes, y su análisis permite comprender los objetivos y la instrumentación de dicha estrategia.

El propósito de este ensayo es contestar dos interrogantes de carácter general acerca de los proyectos de reciprocidad. La primera se refiere a las ra-

\footnotetext{
${ }^{2}$ Barrie, Congress, 1987, pp. 55, 60; Terrill, Tariff, 1973.

${ }^{3}$ En la última década del siglo XIx, Estados Unidos entabló negociaciones comerciales con varios países del continente (Brasil, México, República Dominicana, Guatemala, El Salvador, Nicaragua, Honduras, y con España para Cuba y Puerto Rico; en 1897, Argentina, Ecuador y Nicaragua). Pletcher, "Reciprocity", 1978, pp. 61-62; Topik, Trade, 1996. Laughlin-Willis, Reciprocity, 1901, pp. 312-314.

${ }^{4}$ Véase U. S. Tariff Commission, Reciprocity, 1919.
} 


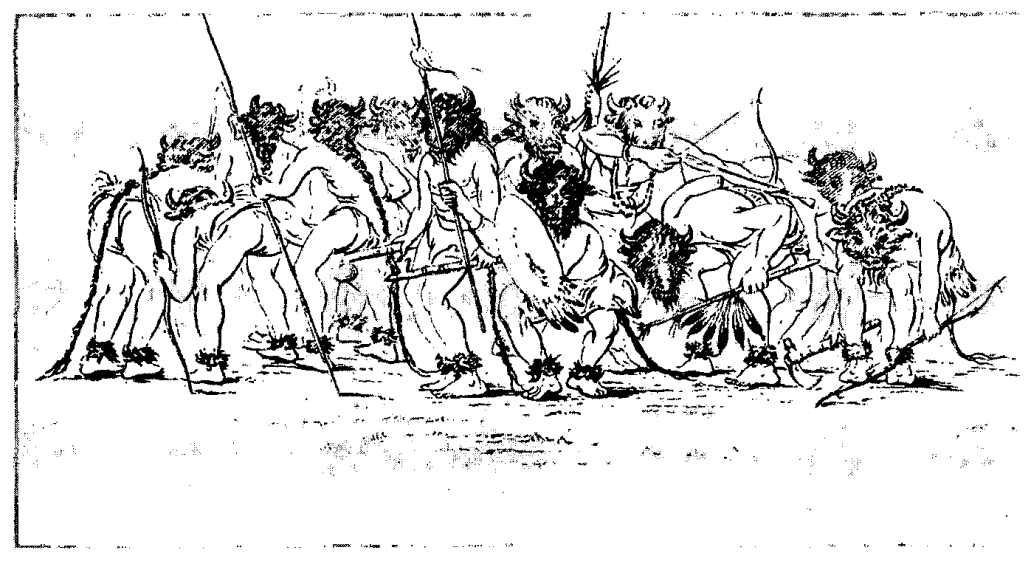

zones primarias de su fracaso. Se trata de explicar por qué los reiterados intentos y esfuerzos de un actor muy superior al otro no lograron concretarse en arreglos bilaterales. Lo que se quiere poner a prueba es la tesis de la pasividad mexicana frente a las propuestas de reciprocidad, y si la dinámica de las decisiones se determinaba enteramente en Estados Unidos. $2 \mathrm{Es}$ posible distinguir otro elemento decisivo en la actitud mexicana en cuanto a aceptación o resistencia hacia tales propuestas? En este sentido, se debe analizar esa dinámica de tipo bilateral, en la que, pese a la asimetría económica y política, México no fue una bola de billar que simplemente rebotaba cuando era tocada por una más grande. ${ }^{5} \mathrm{La}$

'Ésta es la eficaz imagen propuesta por Topik, Trade, 1996, p. 5, para caracterizar una visión en la cual el único elemento activo y relevante en las relaciones económicas con América Latina serían los intereses estadunidenses. segunda interrogante es acerca de la presencia y el papel de elementos extraecónomicos en las decisiones mexicanas acerca de los tratados. Lo que se pretende indagar es el equilibrio entre oportunidades comerciales percibidas y elementos de política internacional e intereses estatales que definió la postura mexicana. La tercera interrogante enfoca el desarrollo de la visión mexicana en relación con la idea de la reciprocidad comercial con Estados Unidos. Se pretende evaluar si hubo relativa continuidad en esta visión o si, al contrario, se pueden detectar cambios significativos en ella y, en este caso, qué clase de elementos los pueden explicar.

El punto de partida es la reconstrucción de la secuencia de negociaciones comerciales entre ambos países y su impacto sobre las relaciones bilaterales. Consideraremos aquí sólo el periodo 1875-1897, excluyendo los Tratados Forsyth-Montes de Oca y McLane-Ocam- 
Cuadro 1. La reciprocidad comercial Estados Unidos-México y sus emergencias

Fechas

1857-1859

1875-1877

$1882-1883$

1891

1897
Negociaciones

Dos tratados:

Forsyth-Montes de Oca

Mclane-Ocampo

Informales:

iniciativa Foster

Tratado Grant-Romero

Formales: Ryan-Limantour

Rechazo preventivo

mexicano
Resultado

Rechazados por el Congreso

de Estados Unidos

Interrupción por revuelta de

Tuxtepec; luego rechazo

mexicano

Ratificado por México pero no por Estados Unidos

No concluidas

Ninguno po. Esta elección se debe al hecho de que éstos tienen características muy diferentes con respecto a las otras negociaciones y se originaron en un pasaje histórico difícilmente comparable con la experiencia posterior a $1867 .^{6}$

A continuación presentaremos la secuencia de los cuatro ciclos de negociaciones comerciales; en cada uno se adopta un grupo de variables clave para contestar las preguntas. El contexto económico en los dos países y el régimen del comercio (niveles del arancel,

\footnotetext{
${ }^{6}$ En ambos casos, el asunto de la reciprocidad estaba envuelto en un paquete de tratados dirigidos a modificar el curso general de las relaciones mexicano-estadunidenses, hasta configurar una estrecha alianza político-económica. La cuestión del intercambio comercial entre los dos países no estaba en el centro de las preocu. paciones económicas y políticas. Véanse Berbusse, "Origins", 1958; Olliff, Reforma, 1981.
}

amplitud del intercambio y cuotas porcentuales) proveen el trasfondo de intereses y equilibrios comerciales que definen el mapa de oportunidades y constreñimientos percibidos. A través de ellos es posible detectar los móviles y los objetivos que llevaron a cada uno de los dos actores a plantear los proyectos y aceptar el terreno de la negociación. El tipo de actores involucrados permite marcar las diferencias entre estilos y concepciones diversas de las relaciones económicas, y el papel de las ideas en la conducción de éstas. Por último están los mecanismos de negociación, a cuyo análisis se dedica especial atención, en la hipótesis de que las actitudes "tácticas" sean reveladoras de las posturas mexicanas y de las correspondientes líneas defensivas adoptadas frente a lo que se percibía como presión estadunidense. 
LA RECIPROCIDAD DULCE: AZÚCAR, MODELO HAWAIANO E INESTABILIDAD POLÍTICA, 1876-1879

Después de la experiencia de 1857. 1859, la coyuntura histórica de los dos países (guerra de Secesión en Estados Unidos, intervención extranjera y guerra contra el imperio en México) desplazó la perspectiva de las posibles negociaciones comerciales bilaterales. Fue a mediados de la década de los setenta cuando se reavivó el interés del gobierno estadunidense por la estipulación de un tratado de comercio con México; a comienzos de 1876 el secretario de Estado Fish autorizó al ministro Foster para que planteara a la Secretaría de Relaciones la posibilidad de un acuerdo de reciprocidad comercial. ${ }^{7}$ Si en los años cincuenta la experiencia de la reciprocidad entre Estados Unidos y Canadá (1854) había estimulado la introducción del tema en las relaciones con México, en la nueva coyuntura, el tratado de reciprocidad con el Reino de Hawai cumplió con la misma fun. ción. Su furma, en 1875, envió la señal de que el gobierno estaba seriamente interesado en los tratados comerciales. ${ }^{8}$ El tratado incluía la admisión libre de derechos de cierto número de

\footnotetext{
${ }^{7}$ Foster a Fish, 29 de enero de 1876 en The National Archives of Washington (en adelante NAW), Despatches from the U. S. Ministers to Mexico, 1823-1906, rollo 53, vol. 55, núm. 373; Devine, John, 1981, p. 21. En junio del mismo año una iniciativa de ley para la reciprocidad comercial con México fue presentada en la cámara de representantes.

${ }^{8}$ En 1855 y 1867 hubo dos intentos fallidos por el rechazo del Congreso. Holt, Treaties, 1964, pp. 102-103.
}

productos de los dos países, pero el protagonista comercial era el azúcar, principal exportación de Hawai y uno de los principales rubros de importación estadunidense.?

El interés por un arreglo comercial fue compartido inicialmente por el gobierno mexicano. Desde su primera etapa al frente de la Secretaría de Hacienda (1868-1872), Matías Romero había sostenido la conveniencia de una estrategia de crecimiento exportador. Como ministro en Washington, difundió las oportunidades que la apertura del mercado estadunidense brindaba al desarrollo de las producciones tropicales mexicanas. ${ }^{10}$

Por otro lado, el interés de la administración de Lerdo de Tejada sobre el tratado comercial tenía móviles políticos: apuntalar un gobierno débil, en crisis de legitimidad, y obtener el apoyo moral y posiblemente financiero del gobierno estadunidense. De hecho, a las discusiones preliminares siguió el proyecto de un préstamo intergubernamental. ${ }^{11}$ Las circunstancias políticas mexicanas (la revuelta de Tuxtepec) inhibieron un desarrollo formal. Pero la primera administración porfirista

${ }^{9}$ U. S. Tariff Commission, Reciprocity, 1919 , pp. 24-25.

${ }^{10}$ En 1875, cuando emergió el asunto de la reciprocidad con Hawai, Romero publicó un estudio sobre el azúcar en México y su exportación. Al año siguiente, sus esfuerzos se incrementaron. Véase Correo del Comercio, 25 de mayo, 4 de julio y 7 de julio de 1876 .

"Foster a Fish, 2 de octubre de 1876 en NAW, Despatches, loc. cit., rollo 55, vol. 57 , núms. 77-80. Foster añadía que el préstamo abriria el camino al tratado comercial, permitiendo así quebrantar el predominio europeo en el mercado mexicano. 
mostró interés en el proyecto y retomó casi de inmediato el asunto; encomendó el examen del tratado con las islas Hawai a una comisión especial, con vistas a una posible extensión a México con base en el Tratado de Amistad y Comercio de $1831 .{ }^{12}$ La comisión, compuesta por hacendados e importadores, lo juzgó negativamente, oponiéndose así al juicio favorable de la Secretaría de Relaciones Exteriores. ${ }^{13}$ Los calificativos de desventajoso, desigual e ignominioso fueron adoptados para definir el tratado. El punto crucial fue la base exportadora del azúcar mexicano y sus mercados. La comisión argumentó que el mercado estadunidense no era ventajoso, debido a la preeminencia del azúcar cubano y que Gran Bretaña y Alemania constituían plazas más favorables; que no había garantía de que Estados Unidos no extendiera el privilegio de la reciprocidad a otros países; y sobre todo, que la capacidad exportadora mexicana era muy precaria. En vista de todo ello, opinó que las oportunidades del azúcar mexicano no ameritaban la concesión de privilegios arancelarios a ningún producto estadunidense.

A partir del surgimiento de la cuestión en esta década, Matías Romero se

${ }^{12}$ Foster a Fish, 23 de febrero de 1877 en Naw, Despatches, loc. cit., rollo 55 , vol. 58 , núm. 497. En el tratado de 1831, los dos países se habian otorgado la cláusula de nación más favorecida. Ello significaba que México hubiera podido pedir la extensión de los privilegios concedidos a Hawai, ofreciendo alguna concesión arancelaria a cambio.

${ }^{13}$ El dictamen de la comisión se puede ver en Diario Oficial, 21 de abril de 1877. Es de notar la presencia en la comisión de José Y. Limantour, futuro secretario de Hacienda. estableció como el principal impulsor, teórico y político, de la reciprocidad comercial con Estados Unidos como vía principal del crecimiento exportador mexicano. Su concepción era en cambio de tipo dinámico, ligada al proceso de reasignación de factores al uso más eficiente y a la posibilidad de enlazar los estímulos de la enorme demanda de Estados Unidos, con las iniciativas empresariales mexicanas. Pero no se trataba de un entusiasmo ingenuo y acrítico: la verdadera dificultad consistía en obtener una reciprocidad sobre bases equitativas, dada la distribución tan asimétrica del poder entre los dos países. ${ }^{14}$

\section{LA RECIPROCIDAD ENTRE INTEGRACIÓN ECONÓMICA Y SOSPECHA POLÍTICA, 1882-1884}

A principios de la década de 1880 , la apertura de comunicaciones ferroviarias entre México y Estados Unidos a través de empresas estadunidenses y el proceso de inversión de capitales proporcionaron el estímulo para replantear el camino de la reciprocidad comercial y formalizar las propuestas. ${ }^{15}$

${ }^{14}$ Secretaría de Hacienda, Memoria, 1877 1878, pp. 61, 68. En esta publicación oficial se afirmaba que el tratado con Hawai había reforzado las preocupaciones existentes en México acerca de la reciprocidad con Estados Unidos. Ibid., p. 71 .

${ }^{15}$ Véanse el informe del enviado especial mexicano en Estados Unidos sobre las conversaciones con Blaine en 1881. Zamacona a Díaz, 10 de marzo de 1881, Colección Porfirio Díaz, leg. 6 , caja 1 , docs. 454-464. Y las indicaciones del secretario de Estado Frelynghuysen a Romero en Archivo Histórico de la Secretaría de Relacio- 


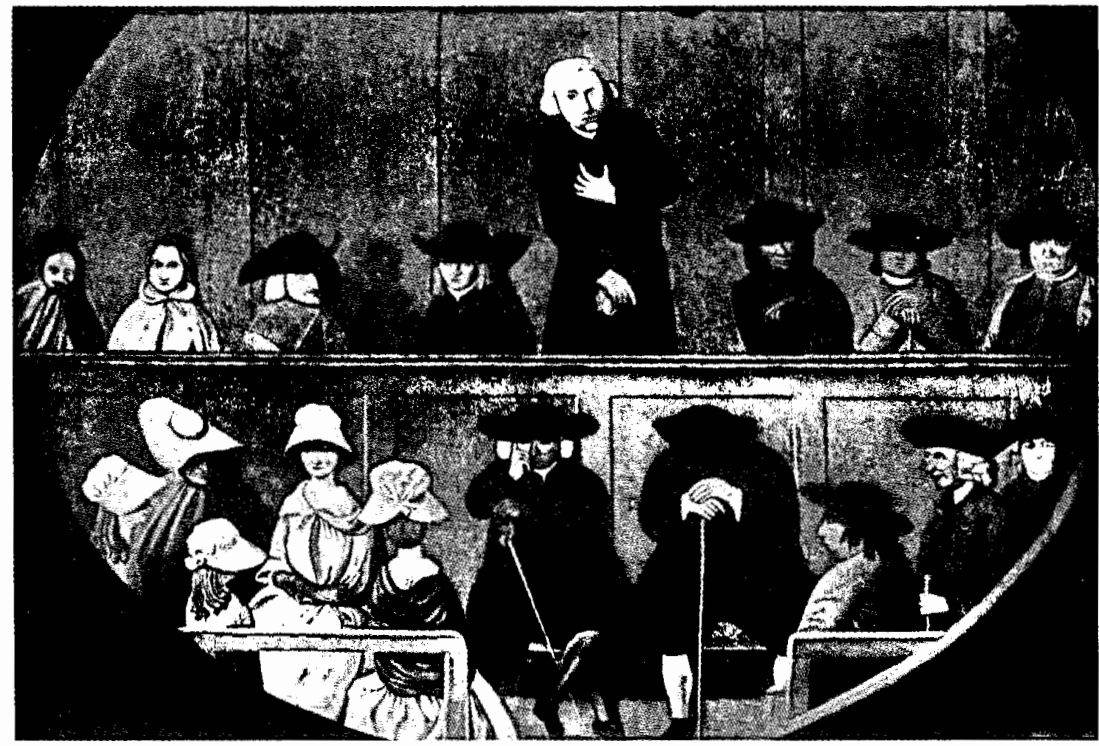

Gracias al enlace ferroviario y al flujo de capitales, la vecindad se había transformado en cercanía geográfica efectiva; la consecuencia fue una súbita reorientación del comercio exterior mexicano. A principios de los años ochenta, Estados Unidos se convirtió de manera permanente en el principal mercado para los productos de México y su principal abastecedor. La apertura de la comunicación ferroviaria tuvo como consecuencia el rápido reacomodo del tráfico comercial entre las dos economías.

nes Exteriores de México (en adelante AHSREM), Archivo de la Embajada Mexicana en Estados Unidos de América (en adelante AEMEUA), t. 324, núm. 505, Romero a Mariscal, 29 de junio de 1882.
En un decenio, la cuota estadunidense en las importaciones mexicanas pasó de $24.5 \%$ a $43.4 \%(+77 \%$ ), y de $38 \%$ a $58 \%$ en las exportaciones $(+53 \%) .{ }^{16} \mathrm{El}$ rápido incremento del intercambio bilateral hizo entrever en Estados Unidos la existencia de oportunidades comerciales importantes al sur del río Bravo, y ello despertó el interés oficial y privado en un arreglo comercial.

En este sentido, México representó el terreno para ensayar una nueva política comercial hacia América Latina. Entre 1883 y 1884 Estados Unidos llevó a cabo negociaciones en tratados de reci-

${ }^{16}$ Cálculos basados en Secretaría de Hacienda, Noticia, 1889; García Cubas, 1889, pp. 72-75; Nimmo, Commerce, 1884. 
procidad con algunos países. Lo que podía perfilarse a comienzos de la década de los ochenta constituía una ola de tratados proyectada para extender, desde México hacia el Caribe y Centroamérica, el predominio comercial estadunidense y dar un significado económico a la Doctrina Monroe. ${ }^{17}$

Las negociaciones de un tratado de reciprocidad comercial, conducidas por el ex presidente de Estados Unidos, Ulysses Grant y por Matías Romero, comenzaron a mediados de 1882 y terminaron en enero de 1883, firmados por los dos gobiernos. La aceptación mexicana de la reciprocidad con Estados Unidos reflejaba la reorientación profunda del intercambio mexicano. La propensión hacia el mercado estadunidense pareció favorable para el propósito mexicano de expandir y diversificar sus exportaciones más allá de los metales preciosos; en cambio los mercados europeos estaban fundamentalmente interesados sólo en la plata. Además, México era un tomador de precios por lo que se refiere a todos sus productos, con una posición muy débil en el mercado internacional, en cuanto a precios y espacios de comercialización. El acceso privilegiado al mercado estadunidense era un recurso de gran valor potencial. En la visión de sus promotores en cambio, la reciprocidad comercial era un modelo de relaciones económicas de interés nacional: "el verdadero sistema comercial ameri-

\footnotetext{
17 Terrill, Tariff, 1973, pp. 41-42; Richardson, Messages, 1902, vol. viII, p. 251. De los tratados que se llegaron a concluir, ninguno entró en vigor por falta de ratificación en Estados Unidos. Holt, Treaties, 1964, pp. 140-141.
}

cano por combinar los mejores elementos de protección y libre comercio"; y simultáneamente atribuir "un contenido comercial a la Doctrina Monroe". ${ }^{18}$

El texto del tratado estipulaba la entrada libre para 27 productos mexicanos a Estados Unidos y de 49 productos estadunidenses a México, con una duración máxima de siete años. El intercambio de privilegios arancelarios, sin embargo, afectaba a menos de $50 \%$ de los productos, ya que en ambos aranceles la mayoría figuraba en la lista libre. ${ }^{19}$ Previsiblemente, la reciprocidad involucraba productos estadunidenses manufacturados y mexicanos no manufacturados, aunque una cuarta parte de las mercancías estadunidenses era de materias primas o alimentos. ${ }^{20}$ El proyecto se basaba en la diferente estructura de las dos economías y trataba de asentarse en los niveles de complementariedad entre ellas. En este sentido, el mayor número de mercancías estadunidenses admitidas reflejaba fundamentalmente un grado muy superior de diversificación y especialización productiva, pero, sobre todo, la diferencia en el tamaño de los mercados. En términos estáticos, lo que se intercambiaba era muy desigual: por un

${ }^{18}$ Palabras de John W. Foster citado en Devine, John, 1981, p. 31. Una exposición del concepto de contenido comercial de la Doctrina Monroe está en el dictamen de minoría del Comité de Medios y Arbitrios del Congreso estadunidense en Romero, Reciprocidad, 1890.

${ }^{19} \mathrm{El}$ análisis del tratado se basa en el texto contenido en Romero, Reciprocidad, 1890.

${ }^{20}$ Avena, azogue, azufre, carbón, frutas, guano, leña, mármol en bruto, paja, petróleo crudo, plantas, verduras. 
lado, el acceso a un mercado enorme respecto a la capacidad productiva mexicana, y con un potencial muy grande de estimulación; por el otro, el acceso a un espacio económico pequeño y no unificado, cuyo crecimiento no podía impulsar de manera relevante las exportaciones estadunidenses.

El tratado reflejaba un concepto reducido de reciprocidad, limitado a productos que eran relativamente secundarios en el intercambio bilateral y, como se ha visto, la liberalización arancelaria era igualmente limitada. Ésta había sido la preferencia mexicana, incorporada fielmente gracias al hecho de que en realidad fue Matías Romero quien elaboró el borrador sobre el cual tuvieron lugar las negociaciones. Sus lineamientos fueron los de restringir los alcances de las concesiones mexicanas, excluyendo tres tipos de productos: los que daban mayor rendimiento al erario, los que se manufacturaban en el país, y los que se importaban, sobre todo de Europa. De esta manera, quedaban a salvo los principales intereses mexicanos, el erario, la industria nacional y los comerciantes-importadores europeos. ${ }^{21}$ La forma restringida de la reciprocidad fue concebida como el punto de equilibrio entre los diferentes intereses que eran potencialmente afectados y capaces de bloquearlo. ${ }^{22}$

\footnotetext{
${ }^{21}$ Romero a SRE, 23 de octubre de 1882, en AHSREM-AEMEUA, t. 328, despacho 1275-II. El perímetro de intereses protegidos fue el que Matías Romero había definido ya en 1877 , como secretario de Hacienda, al abordar la idea de un tratado comercial con Estados Unidos. Secretaría de Hacienda, Memoria, 1877-1878, p. 73.

${ }^{22}$ Romero argumentó que ésta era la única forma posible de arreglo comercial entre los
}

La reconstrucción de los mecanismos de negociación es importante para entender las posiciones mexicanas frente al tratado con Estados Unidos, y el lugar que la cuestión de la reciprocidad comercial ocupó en las relaciones bilaterales. La iniciativa surgió del gobierno estadunidense, con la propuesta de nombrar una comisión mixta que negociara los términos del tratado. Inicialmente, el gobierno del presidente González se opuso a la idea de la reciprocidad comercial y la propuesta de la comisión. ${ }^{23}$ En este punto, el parteaguas fue la escisión de la acción diplomática mexicana en una rama oficial y una privada, ambas gestionadas por Matías Romero. La diplomacia oficial consistió en pedir a los estadunidenses una suspensión de los preliminares. La diplomacia privada se fincó en las relaciones personales de Romero con el ex presidente Grant, comisionado por Estados Unidos para negociar. Este último aceptó que el diplomático mexicano elaborara, de manera extraoficial, un borrador del tratado de reciprocidad que sirviera como base para las negociaciones. De esta manera, el tratado fue creado con base en las principales exigencias mexicanas. Sucesivamente, Romero emprendió una labor de convencimiento de su gobierno y viajó a México a presentar su caso al presidente. Con ciertas dificultades ob-

dos países. Tanto la unión aduanera como la reciprocidad absoluta hubieran sido inaceptables, por limitar e infringir la soberanía y la autonomía de México. Romero, Anexión, 1888 , p. 21.

${ }^{23}$ Mariscal a Romero, telegrama, 7 de agosto de 1882, en AHSREM-AEMEUA, t. 326. 
tuvo finalmente una aprobación del proyecto con algunas modificaciones de la comisión mixta como fórmula. Aparentemente, el punto clave fue el convencimiento de que la reciprocidad restringida no implicaba un sacrificio importante en términos de ingresos fiscales y no constituía un peligro de desequilibrio para el presupuesto federal. Pero la aprobación fue condicionada a que en las negociaciones no se alterara el texto del tratado, sin el consentimiento del gobierno mexicano. ${ }^{24}$

$\mathrm{El}$ asunto de la reciprocidad comercial ciertamente producía trastornos e inquietudes en la relación bilateral, activaba mecanismos de defensa y generaba sospechas políticas; y las del gobierno mexicano se extendieron a la actuación de Romero en Estados Unidos y su desempeño en las futuras negociaciones. La solución ideada fue la de someter el proceso negociador a un estricto control. Durante las reuniones de la comisión mixta la posición mexicana asumió entonces la forma del ultimátum: el texto no era modificable y, en caso contrario, se suspenderían las negociaciones y se cerraría la posibilidad de un acuerdo. ${ }^{25}$

El tratado nunca entró en vigor por falta de aprobación del Congreso estadunidense. ${ }^{26}$ Fue acordado el plazo de

\footnotetext{
${ }^{24}$ Romero, Commercial, 1896.

${ }^{25}$ Cañedo y Romero a Mariscal, 15 de enero de 1883, en AHSREM-AEMEUA, t. 329.

${ }^{26}$ Lamentablemente, en la literatura se ha creado cierta confusión acerca del tratado de reciprocidad, por la incapacidad de distinguir entre la firma por los dos gobiernos y los mecanismos constitucionales necesarios para instrumentarlo. De manera que es frecuente encontrar la información equivocada acerca de que en
}

un año para la ratificación por parte de los respectivos congresos y la promulgación de la legislación necesaria para instrumentarlo. En 1884 fue aprobado por el Senado mexicano y, con más esfuerzo, por el estadunidense, con mayoría de un voto. Pero nunca obtuvo el voto favorable de la Cámara de Representantes de Estados Unidos. ${ }^{27}$ El declive de la actividad económica en 1883, que se transformó en crisis financiera y pánico en $1884,{ }^{28}$ sin duda representó un contexto desfavorable para el establecimiento del tratado comercial. ${ }^{29}$

El fracaso de la reciprocidad se atribuye por lo general a Estados Unidos, cuyo Congreso nunca ratificó el tratado; el peso de los intereses sectoriales y el cambio político (la presidencia demócrata después de 1884), habrían quitado fuerza al proyecto de reciprocidad con México. En realidad, la complejidad de la cuestión fue mucho mayor. La pretensión mexicana fue la de "endosar" a terceros la preferencia aduanal concedida a Estados Unidos; en especial, contribuyó poderosamente a la derrota del tratado en el Congreso de Estados Unidos. ${ }^{30}$

la primera mitad de la década de los ochenta entró en vigor un tratado comercial entre México y Estados Unidos.

${ }^{27}$ Era obligación constitucional, por afectar los ingresos federales.

${ }^{28}$ Para un análisis de la crisis de 1884 en Estados Unidos, véase Sprague, History, 1910.

${ }^{29}$ Romero, Reciprocidad, 1890. En vista de las dificultades con que tropezaba, el plazo de aprobación fue prorrogado dos veces, hasta llegar a 1887, sin que se pudiera llegar ni siquiera a una votación en la cámara baja.

${ }^{30}$ Arriaga, "Tratado", 1996. En el Congreso estadunidense, la mayoría de la comisión de 
En este sentido, la postura mexicana fue la de un actor oportunista. Su interés, más que en la reciprocidad bilateral, se fincaba en las ventajas que ésta podía garantizar dentro de una negociación multilateral que explotara la rivalidad entre las diplomacias europea y estadunidense. El tratado con Estados Unidos fue empleado para extraer mejores términos a la diplomacia europea, por lo que se refiere a objetivos de estatus político. ${ }^{31}$ Aparentemente, éste fue el ápice de la tensión entre las dos dimensiones presentes en la estrategia mexicana: la maximización del prestigio nacional o de la posición en el comercio internacional.

RECIPROCIDAD BAJO REPRESALIA, 1890-1891

El asunto de la reciprocidad comercial reapareció por iniciativa estadunidense entre 1889 y 1891 , bajo el signo del arancel McKinley. Inicialmente la primera Conferencia Panamericana (1889-1890)

Hacienda de la Cámara, formuló una opinión opuesta al tratado: junto consideraciones generales (la pequeñez del mercado mexicano, los niveles tan dispares de desarrollo), subrayó que el artículo quinto, inserto por voluntad mexicana, y que dejaba abierta la posibilidad de extender a otros países los privilegios arancelarios, invalidaba cualquier utilidad del tratado. Romero, Reciprocidad, 1890, p. 23.

${ }^{31}$ La idea mexicana era la de obtener de Francia y Gran Bretaña el reconocimiento de los principios de la Doctrina Calvo (fijados en el Tratado de Amistad con Alemania de 1882) a cambio de la extensión de los privilegios arancelarios otorgados a Estados Unidos. Riguzzi, "México", 1992, pp. 373-374; Arriaga, "Tratado", 1996. fue el espacio de lanzamiento de nuevas propuestas estadunidenses en clave multilateral: el proyecto de la unión aduanera continental, un zollverein interamericano. La iniciativa suscitó las mayores polémicas y oposiciones, ya que la mayoría de los estados latinoamericanos basaba sus finanzas en los ingresos aduanales y, por tanto, no podían aceptarla sin debilitar finanzas de por sí no florecientes. La diplomacia mexicana vio claramente la imposibilidad de realizar algún acuerdo de ese tipo en materia arancelaria, tras su experiencia de fracaso en el tratado comercial bilateral de $1883 .^{32}$ Sucesivamente el éxito nulo de las propuestas de reciprocidad "panamericana" dejó el paso a negociaciones bilaterales.

Sin embargo, en el ínterin, el arancel McKinley de 1890 redefinió abruptamente el argumento de las negociaciones, al introducir por primera vez el elemento de la agresividad arancelaria usada como palanca para obtener concesiones comerciales. En un marco de elevación de tarifas y ante la amenaza de represalias arancelarias, se establecieron condiciones para suscribir acuerdos de reciprocidad comercial con otros países. El arancel asumía la función de instrumento de presión económica y política para obtener la apertura forzada de los mercados latinoamericanos. Específicamente se autorizaba al presidente para imponer derechos punitivos sobre azúcar y miel, café, pieles y té producidos por países culpables de imponer "derechos injus-

${ }^{32}$ Mariscal a Romero, 28 de septiembre de 1889, en AHSREM, Reservada L-E-132-A, t. v. 
tos y no razonables" a las mercancías de procedencia estadunidense. ${ }^{33}$ El cambio en el trasfondo de la política comercial estadunidense fue muy claro: desde la búsqueda de reciprocidad con el fin de obtener materias primas libres para la industria nacional, tal como lo expresara el presidente Cleveland en 1887 , hasta la amenaza de excluir del mercado doméstico a aquellos países que no dieran espacio suficiente a sus exportaciones. De manera opuesta, a partir del arancel de 1887 , la tendencia mexicana había sido reducir cuotas y desgravar artículos. ${ }^{34}$ Esta divergencia entre las dos políticas comerciales reducía de antemano el campo de negociación.

Como había acontecido en 1882, el escenario de las negociaciones comerciales era más amplio, e involucraba a otros países latinoamericanos: pero esta vez México no fue un precursor, sino más bien un campo de aplicación de algo ya experimentado. La administración de Harrison se interesó inicialmente en el acuerdo de un tratado comercial con Brasil, que fue firmado a principios de 1891 y entró en vigor el mismo año. El tratado sirvió como modelo de referencia para las negocia-

${ }^{33} \mathrm{El}$ inspirador de esta estrategia fue nuevamente el secretario de Estado Blaine: en la discusión del arancel McKinley en el Senado logró introducir el apartado sobre los tratados de reciprocidad que no existía en el texto original. Eckes, Opening, 1995, p. 71; Taussig, Tariff, 1967; Topik, Trade, 1996, pp. 28-33.

${ }^{34}$ A pesar de la precariedad de los datos, las proporciones de la rebaja en el nivel promedio del arancel entre 1883-1884 y 1889-1890 son un indicador suficiente de la voluntad liberalizadora. Véase Kuntz, "Institutional", en prensa. ciones con México. ${ }^{35}$ Pero aquí cumplió con la función, revertida, de modelo negativo: el juicio de la prensa económica y de los protagonistas de las negociaciones fue que el tratado imponía a Brasil condiciones desventajosas y vejatorias. ${ }^{36}$ El gobierno mexicano aceptó la negociación de un tratado con su vecino a principios de la década de los noventa, sin embargo, a diferencia de Brasil, ni siquiera la concluyó. ${ }^{37}$ Los encargados de las negociaciones del proyecto de reciprocidad fueron el plenipotenciario estadunidense Ryan y Limantour en calidad de comisionado especial. Las charlas se desarrollaron en México a finales de 1891, y se extendieron durante cuatro meses. Se terminaron con un texto preliminar de acuerdo, pero el asunto fue abandonado. La actitud negociadora mexicana fue similar a la de la discusión del tratado de 1883. Restringió progresivamente el alcance de las propuestas estadunidenses, reduciendo el número de mercancías y fijando condiciones selectivas para su introducción, hasta definir un proyecto de tratado insatisfactorio para el gobierno estadunidense y declarar el fin de las

35 Topik, Trade, 1996. El Tratado BlaineMendoça preveía la entrada libre para quince productos estadunidenses en Brasil y una reducción arancelaria de $25 \%$ para otros once.

${ }^{36}$ Economista Mexicano, 4 de abril de 1891 , p. 93. Véanse las observaciones de Matías Romero, Romero a Limantour, 14 de diciembre de 1891 en Archivo Histórico del Banco de México (en adelante BMéx.), Archivo Matías Romero, Correspondencia despachada.

${ }^{37}$ Ryan a Foster, 6 de agosto de 1891 en NAw, Despatcbes, loc. cit., rollo 103, vol. 109, núm. 726. Mexican Financier Review, 21 de mayo de 1892, p. 199 
negociaciones con un ultimátum. ${ }^{38}$ Las negociaciones se interrumpieron y no fueron reanudadas; la versión oficial mexicana fue que Estados Unidos dejó caer el asunto. ${ }^{39}$ En realidad, los negociadores mexicanos lograron imponer condiciones que no eran aceptables para el gobierno estadunidense, y la cuestión no fue retomada.

Los alcances fuertemente agresivos para México del arancel McKinley indujeron a un replanteamiento de la plataforma de negociaciones comerciales con Estados Unidos: la percepción de los gobernantes mexicanos era que las circunstancias ya no permitían un arreglo equitativo. A pesar de las declaraciones oficiales de disponibilidad formal, la política comercial mexicana renunció a un tratado de reciprocidad con el vecino del norte. Significativamente, el principal defensor mexicano de esa reciprocidad en 1883 fue Matías Romero quien, a principios de los noventa, sugirió la no practicabilidad de tales acuerdos comerciales. ${ }^{40}$ Las exigencias estadunidenses de apertura unilateral del mercado mexicano llegaban hasta el interior del perímetro de seguridad económica nacional: los ingresos federales, la agricultura que producía para el mercado interno y las secciones de la industria manufacturera. Ello provocó una reacción negativa y de rechazo por parte

\footnotetext{
${ }^{38}$ Ryan a Foster, 4 de enero de 1892 , en NAw, Despatcbes, loc. cit., rollo 105, vol. 111.

${ }^{39}$ Mexican Financial Review, 26 de marzo de 1892, p. 292.

${ }^{40}$ Romero a Limantour, 14 de diciembre 1891 en Bméx., Archivo Matías Romero, Correspondencia despachada, $t$. III.
}

de México, que planteó la indisponibilidad hacia la libre importación de tales artículos y también a rebajar la tarifa aduanal, por razones fiscales y de protección. ${ }^{41}$

La experiencia del arancel Mckinley fue una lección muy importante para México, en cuanto a capacidad de defensa y procuración de los intereses nacionales. Uno de los aspectos más agresivos del arancel era la barrera tarifaria a la exportación de minerales argentíferos de baja ley y contenido de plomo, que México exportaba a Estados Unidos, donde se beneficiaban. En respuesta, el gobierno mexicano definió un paquete de incentivos para que fuertes grupos estadunidenses interesados en el comercio de minerales invirtieran en la creación de plantas de beneficio en el norte del país. De esta manera, en lugar de exportar minerales en brùto, se concentró en México el ciclo productivo minerario desde la extracción hasta el beneficio y la fusión. Para la economía mexicana se trató de un beneficio neto: la reorganización espacial y productiva de la actividad minero-metalúrgica produjo un crecimiento muy acelerado de algunas regiones en el norte de México, creando empleos, elevando los salarios y atrayendo población. La posibilidad de instrumentar mecanismos de defensa y amortiguación de la asimetría económica proporcionaba a los gobernantes mexicanos un escenario diferente: no era necesario ceder a las presiones polí-

41 Memorandum of the Mexican Minister, 19 de marzo de 1891, en Bméx., Archivo Matías Romero, Correspondencia recibida, t. III, doc. 38506. 


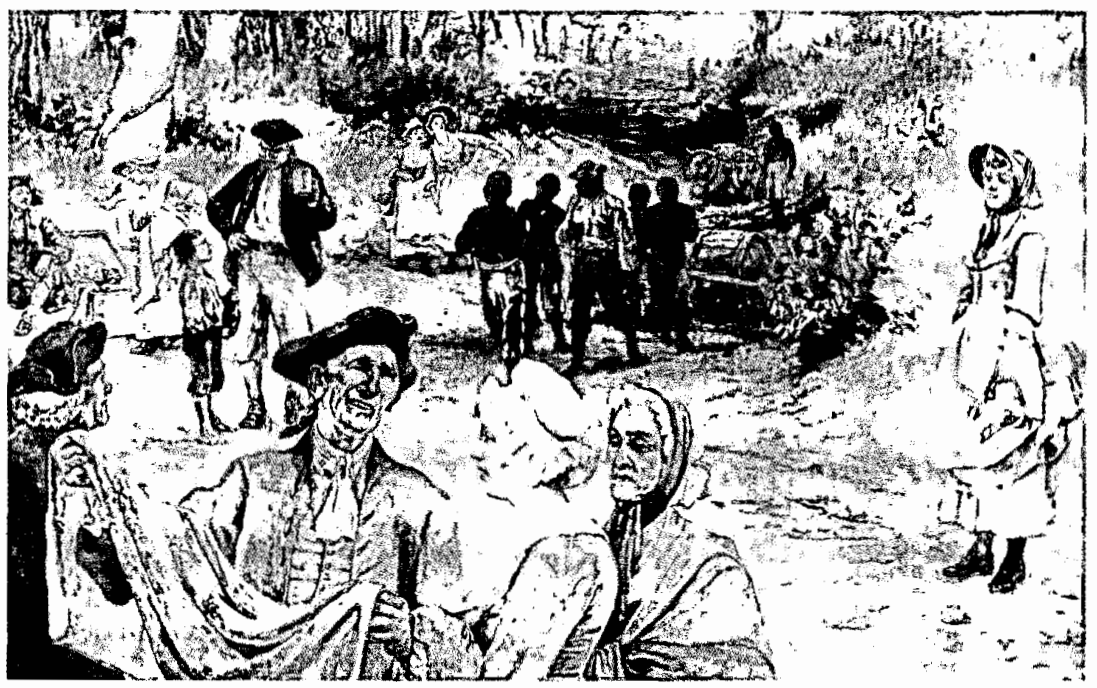

ticas de Estados Unidos que intentaba explotar las ventajas de dicha asimetría.

\section{EL ABANDONO DE LA IDEA DE RECIPROCIDAD EN MÉXICO, 1896-1897}

La nueva emergencia del asunto de la reciprocidad en 1897, al igual que en los casos anteriores, surgió del contexto político y económico estadunidense. El arancel Dingley volvió a incorporar medidas para la estipulación de tratados de reciprocidad bajo la amenaza de establecer derechos punitivos, y al mismo tiempo elevar la altura media de las barreras tarifarias. ${ }^{42} \mathrm{Al}$ mis-

${ }^{42}$ Eckes, Opening, 1995, pp. 75-77; Taussig, Tariff, 1966. El arancel tenía dos mecanismos mo tiempo, en respuesta a las presiones de grupos de productores regionales, se volvía a penalizar una parte del grupo de mercancías mexicanas que habían sido el blanco del arancel McKinley (ganado, frutas y tabaco, entre otras). Éste fue elaborado durante la presidencia de McKinley, en el marco de un programa político de fortalecimiento de los niveles de protección y empleo agresivo de los tratados de reciprocidad.

Las instrucciones del Departamento de Estado a la diplomacia estaduni-

relevantes de presión: facultaba al presidente para imponer derechos adicionales a té, café y vainilla de los países culpables de discriminar los productos estadunidenses; por otro lado lo autorizaba a celebrar tratados de reciprocidad descontando hasta $20 \%$ de las cuotas arancelarias. 
dense fueron las de llamar la atención del gobierno mexicano acerca de los aspectos de reciprocidad comercial en el arancel. ${ }^{43}$ No se trataba de una propuesta formal y no necesitaba formas de presión explícitas: éstas ya estaban incorporadas en el texto del arancel, que prometía penalizaciones para los socios comerciales poco correctos en el tratamiento de los productos estadunidenses, y recompensas para los que aceptaran negociar tratados.

La percepción mexicana fue negativa y se trasladó directamente a la esfera de la respuesta. La iniciativa estadunidense no originó negociación alguna: la reacción mexicana fue evadir y rechazar de inmediato las pretensiones del vecino, en lugar de aceptarlas inicialmente y frenarlas en las negociaciones. Así, la respuesta preventiva del gobierno fue buscar los instrumentos jurídicos y políticos para defender la autonomía comercial mexicana y detener la posible presión estadunidense en favor de un tratado de reciprocidad, ejercido por medio de maniobras arancelarias. ${ }^{44}$ La Secretaría de Hacienda estudió y preparó disposiciones de represalia en caso de que sus exportaciones fueran afectadas por derechos diferenciales de la tarifa estadunidense. ${ }^{45} \mathrm{La}$ solución ideada fue la de una tarifa dual

\footnotetext{
${ }^{43}$ Clayton a Sherman, 12 de agosto de 1897 , y Clayton a Sherman, 20 de agosto de 1897 en NAw, Despatches, loc. cit., caja 97, rollo 125 , vol. 131, núms. 89 y 85 respectivamente.

${ }_{44}$ Mariscal a Limantour, 26 de febrero de 1897 en Centro de Estudios de Historia de México CONDUMEX, Archivo Limantour, rollo 12.

${ }_{45} \mathrm{M}$. Romero a Limantour, 27 de septiembre de 1897, en CONDUMEX, Archivo Limantour, rollo 12 .
}

con cuotas mínimas y máximas aplicables según el socio comercial; esta fórmula se había difundido en Europa en la década de los noventa, especialmente en igual función preventiva, y fue adoptada en Canadá en 1897 en respuesta al arancel Dingley. ${ }^{46}$ Ello sirvió como indicador de la no disponibilidad mexicana para entrar en arreglos arancelarios.

La respuesta fue exitosa, puesto que Estados Unidos dirigió su atención hacia la negociación de tratados comerciales con otros países latinoamericanos, sin que el intento produjera resultados sustanciales ${ }^{47}$ Por otro lado, la amenaza de derechos punitivos no se concretó y los productos mexicanos, aunque afectados por el aumento de los niveles arancelarios, disfrutaron de oportunidades favorables de mercado. ${ }^{48}$ México no tuvo que instrumentar la tarifa dual, y el peligro de guerra arancelaria con el vecino fue evitado.

Esta reacción reflejaba un cambio en la visión de las relaciones comerciales con Estados Unidos. Después de la experiencia de las negociaciones bajo el arancel McKinley, la reciprocidad sólo causaba alarma; el aspecto de la oportunidad para el crecimiento de las exportaciones había desaparecido del mapa mental de los funcionarios gubernamentales. Dicha percepción no se explica por un cambio reconocible

\footnotetext{
${ }^{46}$ Limantour a Romero, 9 de agosto de 1897, en ibid

${ }^{47}$ Fueron negociados once tratados de reciprocidad, pero ninguno de los once tratados fue ejecutado. Holt, Treaties, 1964, pp. 196-197.

${ }^{48}$ La guerra hispanoamericana, circunstancias del mercado internacional y apoyo del gobierno a los productores.
} 
en la estructura de los intereses nacionales mexicanos, pues ni la coyuntura económica ni el estado de las finanzas públicas la imponian o la sugerían. La economía, concluida la etapa de recuperación de la crisis de 1892-1893, se encontraba en una etapa de auge, el déficit presupuestal había desaparecido y el peso de los ingresos aduanales en el presupuesto federal disminuyó significativamente, cayendo por primera vez por debajo de $50 \%$. Este último indicador garantizaba mayor espacio de maniobra para posibles concesiones arancelarias. ${ }^{49}$

La visión negativa de la reciprocidad con Estados Unidos tuvo su origen en las ideas del protagonista del auge económico: el secretario de Hacienda, José Y. Limantour. Pese a que la interpretación necesita profundizarse y afinarse, nuestra hipótesis es que sus opiniones procedían de una concepción del crecimiento económico diferente a la de Matías Romero. ${ }^{50} \mathrm{La}$ aceptación de es-

\footnotetext{
${ }^{49}$ En el cuatrienio 1892-1895 (años fiscales que empiezan el primero de julio), los derechos de importación significaron $\mathbf{4 2 \%}$ de los ingresos federales ordinarios; en los dos cuatrienios anteriores (1884-1887, 1888-1891), el porcentaje habia sido respectivamente de $55 \%$ y $54 \%$. Cálculos basados en los datos de las Memorias anuales de la Secretaría de Hacienda.

${ }^{50}$ Limantour sucedió a Matías Romero como secretario de Hacienda. El ideario económico de estas dos figuras contrasta marcadamente. El enfoque de Romero tuvo como centro la idea de ventaja comparativa, propagada e impulsada mediante el esfuerzo de promoción de las exportaciones agrícolas. En Limantour, en cambio, la ventaja comparativa no funcionaba como un principio ordenador. El concepto no está presente, ni implícitamente, en sus palabras; su interés en el crecimiento del sector indus-
}

tas ideas por el gobierno se debía al estatus político superior: Limantour gozaba de prestigio y primacía dentro del gabinete. A diferencia de ocasiones anteriores, el centro de las decisiones estaba en la Secretaría de Hacienda y no en la de Relaciones. La postura de Limantour frente a la perspectiva de negociaciones de reciprocidad fue muy negativa. ${ }^{51}$

En su opinión, "dadas las condiciones políticas, geográficas y económicas", el objetivo primario era el mantenimiento de alguna distancia comercial frente a Estados Unidos y la defensa de la vinculación con los países europeos. ${ }^{52}$ Cualquier arreglo comercial bilateral se consideraba perjudicial; impulsar el comercio con Estados Unidos a través de arreglos especiales significaría convertirse en "mercado tributario de las industrias de aquella nación $[. .$.$] ponien-$ do sus productos a cubierto de toda competencia extranjera". ${ }^{53}$ La política mexicana debía ser la de cultivar relaciones comerciales amplias con los otros países y extender la apertura al comercio extranjero. La interpretación limantouriana sobre Estados Unidos estaba más enfocada al poder potencialmente hostil que al mercado potencialmente favorable; en consecuencia, prudencia y actitud defensiva, $y$ no apertura y búsqueda de posiciones comerciales eran las líneas de conducta.

trial y la imposición de derechos de exportación a varios productos, lo confirman. Desarrollaremos este argumento en otro trabajo.

${ }^{51}$ Limantour a Mariscal, 25 de febrero de 1897, en CONDUMEX, Archivo Limantour, rollo 9.

${ }^{52}$ Limantour a Romero, 6 de enero de 1897, en ibid., rollo 10.

${ }^{53} \mathrm{Ibid}$. 


\section{CONCLUSIONES}

El primer objetivo de este estudio es conocer las razones por las cuales los esfuerzos para asentar un régimen de reciprocidad comercial entre México y Estados Unidos durante la segunda mitad de siglo XIX no produjeron resultados concretos. En los casos analizados, la cuestión de la reciprocidad comercial se originó siempre por iniciativa diplomática estadunidense. Sin embargo, las circunstancias muy variables de su política acerca de este punto son difíciles de interpretar en el marco de un proyecto coherente de expansión comercial por medio de arreglos diplomáticos. Como aconteció en otros casos de acuerdos con países latinoamericanos, no ofrecieron perspectivas de consolidación al camino de la reciprocidad. Pero el análisis permite afirmar que la actitud y las posturas mexicanas fueron relevantes, y en tres casos, decisivas para definir el camino del tratado comercial.

Entre 1877 y 1879 , el primer gobierno porfirista descartó la aplicación del modelo hawaiano a México, así como un tratado que vinculara el comercio con el reconocimiento diplomático. En los quince años sucesivos, la reciprocidad compareció dos veces en las relaciones bilaterales y produjo dos negociaciones formales $e$ incluso la firma de un tratado (en 1883). En los dos casos, la respuesta mexicana tuvo un rasgo común que, con diferente intensidad, conformaba una estrategia de contención de la presión estadunidense. Se trataba de la aceptación condicional del terreno de las negociaciones, y del freno impuesto desde adentro a los alcances comerciales de éstas. La "reciprocidad reducida", formulada por Matías Romero, desempenó un papel considerable en los resultados finales de las negociaciones de 1883 y 1891 . En el tratado de 1883 la limitada importancia de los artículos incluidos en la lista libre, y sobre todo, la pretensión mexicana de multilateralizar los privilegios arancelarios, fueron argumentos de peso en determinar la negativa del Congreso estadunidense. En 1891, el número pequeño de bienes y el rechazo a la inclusión de manufacturas definieron un texto provisional inaceptable para los intereses estadunidenses, deseosos de obtener la apertura de los mercados latinoamericanos por medio del arancel McKinley. En ambos casos, el gobierno mexicano impuso también un plazo temporal rígido para las negociaciones, decretando, de hecho, su cese repentino. En 1897, en cambio, el escenario cambió: los supuestos y la actitud mexicana ya no eran compatibles con la aceptación de la idea estadunidense de reciprocidad. La defensa de la presión política y arancelaria exterior se hizo fuera del terreno de las negociaciones, aun aceptando el riesgo de una guerra comercial con el poderoso vecino.

En cada uno de los casos estudiados es posible detectar del lado mexicano la combinación de razones comerciales, intereses estatales y política internacional con diferentes equilibrios entre sí. En la relación de México con Estados Unidos, la dimensión económica se percibía con fuertes imbricaciones con la seguridad nacional y la autonomía en la toma de decisiones; es decir, su desincorporación de los aspectos políti- 
cos y estratégicos era sólo parcial. Por tanto, las concesiones de apertura en los mercados, aunque fueran recíprocas y pudieran parecer un aspecto eminentemente comercial, evocaban temores e inquietudes políticas.

En este sentido, las experiencias de negociación comercial ponen en evidencia que el proyecto agroexportador no era exclusicamente la prioridad de la política gubernamental, sino que había otro tipo de consideraciones que moldeaban las preferencias mexicanas. Estados Unidos representaba el mercado principal para el comercio exterior mexicano, pero ello no era suficiente para despojar de frenos políticos y diplomáticos la búsqueda de mayores y mejores vinculaciones comerciales.

La presencia constante de "sombras" políticas en la visión de reciprocidad comercial con el poderoso vecino, no significa sin embargo que la postura mexicana haya sido uniforme y estable. Hubo una modificación importante en la visión oficial que enmarcó la relación comercial con Estados Unidos dentro de la agenda mexicana, que se puede detectar emblemáticamente a través del contraste entre las ideas de dos protagonistas de dicha visión: Matías Romero y José Y. Limantour. El aspecto central del cambio entre sus percepciones, era la reorientación de las prioridades mexicanas. Dentro de este marco, la vieja idea de Romero del mercado estadunidense como una oportunidad extraordinaria para el crecimiento exportador, había perdido su atractivo en los círculos gubernamentales. La prudencia defensiva había desplazado a la confianza de la apertura comercial. La reorientación implicaba un reorde- namiento de posiciones entre intereses públicos y privados. El Estado, y no el comercio, debía ser el centro de la perspectiva: la autonomía en la toma de decisiones se consideraba preferible a las ganancias privadas obtenibles por medio del comercio.

\section{ARCHIVOS \\ NAW . The National Archives of Wash- ington. \\ AHSREM Archivo Histórico de la Secre- taría de Relaciones Exteriores de México. \\ Condumex Centro de Estudios de Histo- ria de México CONDUMEX. \\ BMéx Archivo Histórico del Banco de México.}

\section{Periódicos}

-Correo del Comercio, 1876.

-Diario Oficial, 1877-1883.

-Economista Mexicano, 1886-1897.

-Mexican Financier, 1883-1892.

-Mexican Financial Review, 1892.

\section{BIBLIOGRAFÍA}

-Arriaga, Víctor, "El tratado de reciprocidad comercial entre México y Estados Unidos de 1883" en Borja, Limites, 1996.

-Berbusse, "The origins of the McLaneOcampo Treaty of 1859", The Americas, vol. 14, núm. 3, 1958.

-Barrie, Robert, Congress and the executive: the making of United States foreign trade policy, 1789-1968, Nueva York-Londres, 1987.

-Borja, Arturo, Guadalupe Rodríguez y Brian Stevenson (coords.), Los límites del neorrealismo, CIDE-Porrúa, México, 1996. 
-Bortz, Jeffrey y Haber Stephen (comps.), Institutional change and economic growth. A new economic bistory of Mexico, Stanford University Press, Stanford, en prensa.

-Devine, Michael J., John W. Foster. Politics and diplomacy in the imperial era, 1873-1917, Ohio University Press, AtenasLondres, 1981.

-Eckes, Alfred Jr., Opening America's market. U.S. foreign trade since 1776, University of North Carolina Press, Chapel Hill-Londres, 1995.

- Gurza Lavalle, Gerardo, El tratado de reciprocidad comercial. Catálogo de documentos en el Arcbivo de la Embajada de México en los Estados Unidos de América, Instituto Mora/Instituto de Investigaciones Históricas-UNAM, México, 1995.

-Holt, W. Stull, Treaties defeated by the Senate. Study of the struggle between the president and Senate over the conduct of foreign relations, Peter Smith, Gloucester, Mass., 1964.

-Lake, David, Power, protection and free trade. The international sources of U.S. commercial strategy, 1889-1940, Cornell University Press, 1988.

-Kuntz, Sandra, "Institutional change and foreign trade in Mexico, 1870-1911" en Bortz y Haber, Institutional, op. cit.

-Laughlin, Laurence y $\mathrm{H}$. Parker Willis, Reciprocity, The Baker \& Taylor Co., Nueva York, 1903.

-Martí, José, Obras completas, Nuestra América, La Habana, 1963, vol. 6.

-Moore, John Bassett, Principles of american diplomacy, Harper \& Brothers, Nueva York-Londres, 1918.

-Nimmo, Joseph, The commerce between the United States and Mexico, Government Printing Office, Washington, 1884.

-Olliff, Donathon, Reforma Mexico and the United States. The search for alternatives to a annexation, 1854-1861, University of Alabama Press, 1981.

-Pletcher, David, "Reciprocity and Latin
America in the early 1890s: foretaste of dollar diplomacy", Pacific Historical Review, vol. XIVII, núm. 1, 1978.

-Richardson, James, A compilation of the messages and papers of the presidents of the United States, Bureau of National Literature, Nueva York, 1902.

-Riguzzi, Paolo, "La difícil evolución de una relación a tres. México, Estados Unidos, Gran Bretaña, 1867-1910", Historia Mexicana, vol. XII, núm. 163, 1990.

, "John Foster" en Ana Rosa Suárez (coord.), En nombre del destino manifiesto, op. cit.

-Romero, Matías, La anexión de México a los Estados Unidos, Imprenta del Gobierno, México, 1888.

-_, Reciprocidad comercial, Oficina Tipográfica de Fomento, México, 1890. ween Mexico and the United States, 1896, ms.

Mexico and The United States, Putnam and Sons, Nueva York-Londres, 1898.

-Salvucci, Richard, "The origin and progress of U.S.-mexican trade, 1825-1884: Hoc opus, hic labor est", Hispanic American Historical Review, vol. 71, núm. 4, 1991.

-Secretaria de Hacienda, Memoria, México, varios años fiscales.

- Noticia de la importación $y$ exportación de mercancias en los años fiscales de 1872 a 1873,1873 a $1874 y$ 1874 a 1875, Gonzalo Esteva, México, 1889.

-Sprague, O. M. W., History of crises under the National Banking System, Washington, 1910.

-Suárez, Ana Rosa (coord.), En nombre del destino manifiesto. Guia de ministros y embajadores en México, Instituto Mora/SRe, México, 1998.

-Taussig, Fred, Tariff bistory of the United States, A. M. Kelley Publishers, Nueva York, 1967. 
-Terrill, Tom, The tariff, politics and american foreign policy, 1874-1901, Greenwood Press, Westport, Conn., 1973.

-Topik, Steven, Trade and gunboats. The United States and Brazil in the age of empire, Stanford University Press, Stanford, 1996.
-United States, 82D Congress, Inaugural messages of the presidents of the United States, Washington, 1950.

-United States Tariff Commission, Reciprocity, Washington, 1919. 